\title{
MASALAH DALAM PENGELOLAAN KOTA LAMA SEMARANG SEBAGAI NOMINASI SITUS WARISAN DUNIA
}

\author{
Ardiana Yuli Puspitasari ${ }^{1)}$ \\ Wa Ode Sitti Khasanah Ramli ${ }^{2)}$ \\ Prodi Perencanaan Wilayah dan Kota Universitas Islam Sultan Agung Semarang ${ }^{1), 2)}$ \\ Penulis Korespondensi e-mail : ardiana@unissula.ac.id
}

\begin{abstract}
World Heritage Sites is a term addressed to special places such as national parks, forests, mountains, lakes, deserts, buildings, complexes, regions, rural and cities that have been nominated by UNESCO (United Nations Educational, Sciencetific, and Cultural Organization) for the International World Heritage program. The Old City of Semarang in 2016 has entered as one of the nominees of World Heritage Site and until now is in the process of submitting terms to become World Heritage Site. One of the important things that need to be done in the process is to identify and inventory the problems to be handled immediately. The purpose of this research is to find the problems in the management of the Old City of Semarang so that it can be handled and anticipated. The research method used is qualitative rationalistic with empirical approach. The results of this research are the problems that occur in the Old Town of Semarang is quite complex and diverse, among others: 1) environmental problems, namely prone to natural disasters (rob floods and puddles), high traffic volume causes pollution of fading and vibration, the unavailability of public transportation "ngetem" space, lack of provision of infrastructure and facilities and open green spaces; 2) building problems, ie there are still vacant buildings that have not been utilized properly, the building owner / user neglect, the utilization of buildings that are inconsistent with preservation rules, and the lack of maintenance of buildings; 3) social problems, that is the existence of homeless / homeless who occupy abandoned buildings, street vendors, excessive tourist attraction and crime; 4) governance issues, namely lack of clarity of tupoksi and authority of Semarang City Old Town, lack of coordination among stakeholders, and less implementation of RTBL policy regulation of Kota Lama Semarang (Regional Regulation Number 8 of 2003).

Keywords: problem, management, site, heritage, world
\end{abstract}

\begin{abstract}
ABSTRAK
World Heritage Sites atau Situs Warisan Dunia merupakan istilah yang ditujukan kepada tempat khusus seperti taman nasional, hutan, pegunungan, danau, gurun pasir, bangunan, kompleks, wilayah, pedesaan, dan kota yang telah dinominasikan oleh UNESCO (United Nations Educational, Sciencetific, and Cultural Organization) untuk program Warisan Dunia Internasional. Kota Lama Semarang pada tahun 2016 sudah masuk sebagai salah satu nominasi World Heritage Site dan sampai dengan saat ini sedang berproses untuk pengajuan syarat-syarat menjadi World Heritage Site. Salah satu hal penting yang perlu dilakukan dalam proses tersebut adalah mengindentifikasi dan menginventarisasi permasalahan agar bisa segera ditangani.Tujuan dari penelitian ini adalah menemukan permasalahan-permasalahan dalam pengelolaan Kota Lama Semarang sehingga bisa segera ditangani dan diantisipasi. Metode penelitian yang digunakan adalah kualitatif rasionalistik dengan pendekatan empiris. Hasil yang ditemukan dari penelitian ini adalah permasalahan yang terjadi di Kawasan Kota Lama Semarang cukup kompleks dan beragam, antara lain: 1) masalah lingkungan, yaitu rawan terhadap bencana alam (banjir rob dan genangan), volume lalu lintas yang tinggi menyebabkan polusi udaran dan getaran, belum tertatanya ruang "ngetem" angkutan umum, kurangnya penyediaan infrastruktur dan fasilitas serta ruang terbuka hijau; 2) masalah bangunan, yaitu masih terdapat bangunanbangunan kosong terlancar dan belum dimanfaatkan dengan tepat, pembiaran bangunan oleh pemilik/pengguna, pemanfaatan bangunan yang tidak sesuai dengan kaidah pelestarian, dan kurangnya perawatan bangunan; 3) masalah sosial, yaitu masih adanya gelandangan/tuna wisma yang menempati bangunan-bangunan terlantar, pedagang kaki lima, tarikan wisata yang berlebihan dan kriminalitas; 4) masalah tata kelola, yaitu kurang jelasnya tupoksi dan kewenangan pengelola Kawasan Kota Lama Semarang, kurangnya koordinasi antar stakeholder, dan kurang implementatif peraturan kebijakan RTBL Kota Lama Semarang (Perda No. 8 tahun 2003).
\end{abstract}

Kata kunci: masalah, pengelolaan, situs, warisan, dunia 
Jurnal Planologi Vol. 15, No. 1, April 2018

Available : http://jurnal.unissula.ac.id/index.php/psa

\section{PENDAHULUAN}

World Heritage Sites atau Situs Warisan Dunia merupakan istilah yang ditujukan kepada tempat khusus seperti taman nasional, hutan, pegunungan, danau, gurun pasir, bangunan, kompleks, wilayah, pedesaan, dan kota yang telah dinominasikan oleh UNESCO (United Nations Educational, Sciencetific, and Cultural Organization) untuk program Warisan Dunia Internasional. Sebuah situs warisan dunia adalah suatu tempat budaya dan alam, serta benda yang memiliki arti penting bagi umat manusia dan menjadi sebuah warisan bagi generasi yang akan datang. Program ini bertujuan untuk menginventarisasi, menamakan, dan melestariakn tempat-tempat yang sangat penting agar menjadi warisan manusia dunia.

Kawasan bersejarah atau kota lama di Indonesia mengalami tekanan pembangunan, bahkan aset budaya berupa bangunan dan kawasan kota lama/tua terancam oleh modernisasi. Pembangunan kota yang kurang dapat mengakomodasi kepentingan budaya, dan hanya berkonsentrasi pada pembangunan ekonomi seringkali mengakibatkan kota tidak lagi menyisakan warisan bersejarah. UU No. 11 tahun 2010 tentang Cagar Budaya secara eksplisit sudah menyatakan keberadaan kawasan cagar budaya, namun operasionalisasi dan implementasi proses perlindungan masih terbuka lebar. (Adhisakti, 2013).

Kota Semarang memiliki catatan sejarah dan aset pusaka sebagai salah satu pembentuk karakter kota. Kota Semarang menjadi pusat distribusi barang di Pulau Jawa dalam percaturan perdagangan dunia pada akhir abad 18 - awal abad 20, yang sangat berharga dan harus dilestarikan dan dipikirkan keberlanjutannya. Posisi kota Semarang pada waktu itu menjadi sangat penting dan vital, dalam percaturan perdagangan dunia, karena Jawa memiliki komoditas penting dan spesifik yang dibutuhkan dunia, terutama komoditas gula, tembakau, indigo, kopi, teh, karet, dan rami (rosela) yang pendistribusian ke luar menuju jaringan perdagangan dunia melalui Pelabuhan Kota Semarang. Semakin besar dan ramainya kegiatan perdagangan di Kota Semarang berdampak pada pengembangan jalur transportasi untuk distribusi komoditas perkebunan dan industri gula dari daerah pedalaman Jawa, diantaranya dikembangkannya transportasi Kereta Api (jalur rel Kereta Api beserta stasiun-stasiunnya) di pusat-pusat kota penghasil produk perkebunan vital tersebut. Hal ini juga berdampak pada pertumbuhan Kota Semarang beserta fasilitas pendukungnya, seperti bank dan kantor-kantor dagangnya, konsulat, asuransi, gudang, kantor pemerintah Belanda, permukiman kolonial, tempat ibadah, dan lain sebagainya. 
Sebagian besar artefak/aset yang terkait dengan masa kejayaan perdagangan di Kota Semarang masih bisa dilihat dan dipelajari di Kota Lama Semarang dan pada tahun 2016 Kota Lama Semarang sudah masuk sebagai salah satu nominasi World Heritage Site dan sampai dengan saat ini sedang berproses untuk pengajuan syarat-syarat menjadi World Heritage Site. Salah satu hal penting yang perlu dilakukan dalam proses tersebut adalah mengindentifikasi dan menginventarisasi permasalahan yang ada di dalam Kota Lama agar bisa segera ditangani dan terus dijaga keberlanjutan pengelolaan permasalahan tersebut.

\section{METODOLOGI}

Metode pendekatan dalam penelitian ini adalah kualitatif rasionalistik dengan metode analisis deskriptif empirik. Metode kualitatif rasionalistik yang dimaksud dalam penelitian ini adalah berfikir rasional sehingga bisa diterima oleh logika akal manusia dan didasari oleh konsep-konsep teoritik penting. (Muhadjir, 2000). Adapun parameter dalam penelitian ini adalah:

Tabel 1. Parameter dan Variabel

\begin{tabular}{|l|l|l|}
\hline No & \multicolumn{1}{|c|}{ Parameter } & \multicolumn{1}{c|}{ Variabel } \\
\hline 1. & Fisik Lingkungan & $\begin{array}{l}\text { 1. Kerawanan terhadap bencana alam } \\
\text { 2. Kerawanan terhadap aktivitas yang berlebihan }\end{array}$ \\
& & $\begin{array}{l}\text { 3. Aktor yang berperan } \\
\text { 4. Penyediaan infrastruktur dan fasilitas }\end{array}$ \\
\hline 2. & Bangunan & $\begin{array}{l}\text { 1. Pemanfaatan bangunan } \\
\text { 2. Kondisi bangunan }\end{array}$ \\
& & $\begin{array}{l}\text { 3. Kepemilikan bangunan } \\
\text { 4. Tata cara penanganan dan pemanfaatan bangunan }\end{array}$ \\
\hline 3. & Sosial & $\begin{array}{l}\text { 1. Aktivitas sosial yang berdampak negatif terhadap } \\
\text { kawasan }\end{array}$ \\
& & $\begin{array}{l}\text { 2. Aktivitas wisata yang tumbuh dan berkembang } \\
\text { 3. Ancaman kriminalitas }\end{array}$ \\
& & $\begin{array}{l}\text { 4. Keberadaan masyarakat yang bukan penghuni } \\
\text { kawasan }\end{array}$ \\
\hline 4. & Tata Kelola & $\begin{array}{l}\text { 1. Posisi, peran, dan kewenangan pengelola kawasan } \\
\text { 2. Sistem kerjasama dan koordinasi antar stakeholder } \\
\text { 3. Peraturan kebijakan yang berpengaruh pada kawasan }\end{array}$ \\
\hline
\end{tabular}

\section{PEMBAHASAN}

\section{A. Kawasan Kota Lama yang mengalami kebuntuan pertumbuhan}

Identifikasi dan inventarisasi permasalahan pada atribut ini digunakan sebagai upaya untuk langkah awal untuk menemukan strategi penanganan masalah sehingga bisa mendorong pertumbuhan Kawasan Kota Lama, dengan memperhatikan 'daya jual' 
sejarah dan budaya. Untuk meningkatkan daya jual kawasan dilakukan dengan 3 pendekatan yaitu:

- Mempertahankan Citra Kawasan Kota Lama (prinsip-prinsip otentisitas)

- Mendorong kegiatan didalam kawasan Kota Lama dengan kegiatan yang mampu meningkatkan ekonomi (prinsip-prinsip adaptive re-use).

- Penguatan sistem pengelolaan melalui Badan Pengelola yang mampu bekerja sama dengan para stake holder (prinsip-prinsip manajemen yang profesional)

\section{B. Penataaan Sistem Sirkulasi}

Sistem sirkulasi di Kawasan Kota Lama sangat dipengaruhi oleh batasan-batasan bangunan bersejarah yang tidak memungkinkan dilakukan perubahan. Jalan sempit dan tidak memungkinkan diperlebar sebagai salah satu bentuk hambatan, sehingga sistem sirkulasi relaif sulit dilakukan.

\section{Kekhawatiran Perubahan Keseimbangan Lingkungan}

Lingkungan menjadi salah satu isu strategis lain dalam penataan kawasan Kota Lama. Keseimbangan tata air terutama menjadi permasalahan utama pada kawasan ini. Ketiadaan ruang terbuka hijau menjadi ancaman utama menurunnya resapan air ke dalam sistem air tanah kawasan.

Terdapat 3 (tiga) elemen utama yang mempengaruhi permasalahan-permasalahan di dalam Kawasan Kota Lama, yaitu:

\section{A. Bangunan}

Kondisi bangunan-bangunan konservasi yang ada di Kota Lama sebagian dalam keadaan : kosong (tidak berfungsi), kondisi tidak terawat, kondisi rusak dan telah roboh, Kawasan Kota Lama merupakan kawasan yang menjadi saksi perkembangan kota. Transisi wajah kota terekam di sepanjang koridor Kawasan Kota Lama; dimana terjadi kegiatan ekonomi, sosial, budaya dan wisata yang saling mendukung, dan Kawasan Kota Lama merupakan kawasan wisata yang menjadi fokus utama kunjungan wisata dan menjadi area transit ke kawasan wisata lain. 
Jurnal Planologi Vol. 15, No. 1, April 2018

Tabel 2 Permasalahan Bangunan Pada Kawasan Kota Lama Semarang

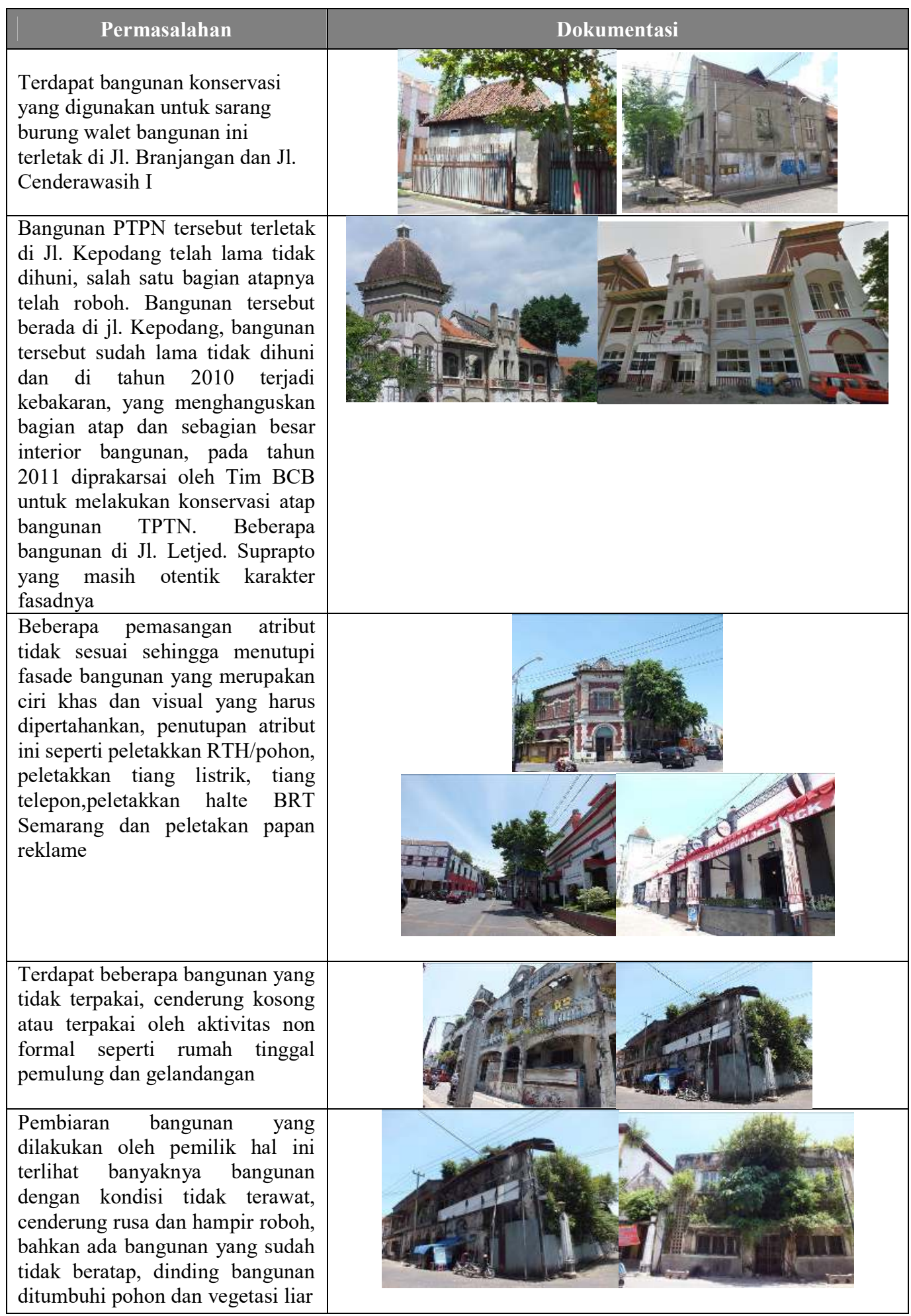




\begin{tabular}{|l|l|}
\hline \multicolumn{2}{|c|}{ Permasalahan } \\
\hline Terdapat bangunan baru yang \\
berada di kawasan bangunan \\
konservasi, desain bangunan baru \\
ini tidak memperhatikan nilai \\
karakteristik Kawasan Kota Lama \\
sebagai kawasan heritage
\end{tabular}

Sumber: Survey Primer, 2016-2017

\section{B. Lingkungan}

Kawasan Kota Lama Semarang sangat rentan terhadap bahaya banjir. Ada dua kategori banjir yaitu banjir yang menggenang di titik-titik tertentu dan banjir yang mengalir di dalam kawasan. Banjir yang yang terjadi tersebut mengganggu aktivitas, pergerakan lalu lintas di kawasan Kota Lama dan sekitarnya. Selain itu banjir ini juga dapat merusak infrastruktur dan mempengaruhi ketahanan bangunan-bangunan yang ada.

Tabel 3. Permasalahan Lingkungan Pada Kawasan Kota Lama Semarang

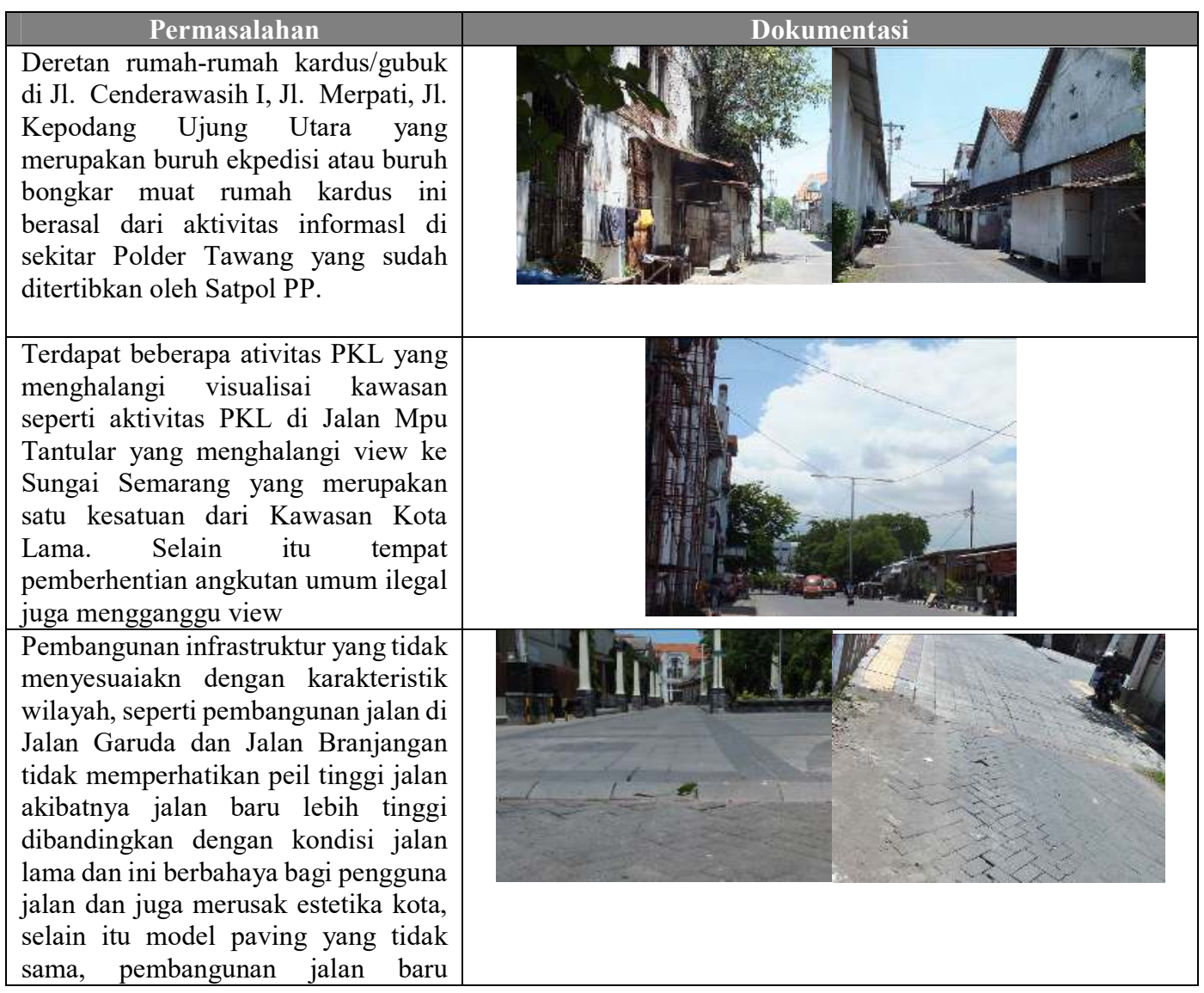


Jurnal Planologi Vol. 15, No. 1, April 2018

\begin{tabular}{|c|c|}
\hline Permasalahan & Dokumentasi \\
\hline $\begin{array}{l}\text { menggunakan model paving persegi } \\
\text { dengan ukuran } 25 \times 25 \mathrm{~cm} \text {, dengan } \\
\text { model pemasangan ini maka tida } \\
\text { dapat menahan beban jalan dan } \\
\text { nantinya jalan paving ini akan } \\
\text { bergelombang }\end{array}$ & \\
\hline $\begin{array}{l}\text { Terjadi over atraction atau } \\
\text { pengunjung dan aktivitas yang } \\
\text { berlebihan pada satu titik, saat ini } \\
\text { aktivitas hanya terpusat di sepanjang } \\
\text { Jalan Soeprapto terutama di kawasan } \\
\text { Taman Srigunting nantinya } \\
\text { dikawatirkan aktivitas yang } \\
\text { berlebihan akan merusak lingkungan }\end{array}$ & 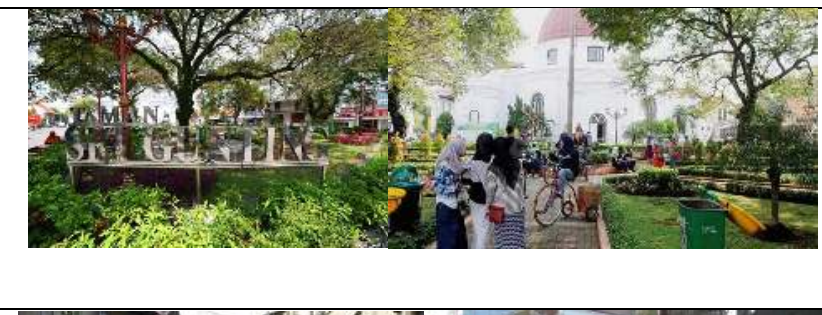 \\
\hline $\begin{array}{l}\text { Termasuk daerah Akuifer Produktif } \\
\text { dengan Penyebaran Luas mencapai 5- } \\
10 \text { liter/detik (Kelurahan Tanjung } \\
\text { Mas, Bandarharjo dan Kuningan), } \\
\text { memiliki akuifer produktif tinggi yang } \\
\text { mencapai lebih dari } 10 \text { liter/detik } \\
\text { sangat berpotensi mengakibatkan } \\
\text { timbulnya Genangan Air Laut/ Rob, } \\
\text { kedalaman Sumur rata-rata 3-10 } \\
\text { meter, daerah genangan/ rob dengan } \\
\text { ketinggian rata-rata } 20-60 \mathrm{~cm} \text {, dengan } \\
\text { lama genangan 2,5-7 jam, penetrasi } \\
\text { air laut mencapai } 11-15 \text { meter, pada } \\
\text { jarak 3,5 Km dari Garis Pantai, } \\
\text { kedalaman Air Payau 1-10 meter pada } \\
\text { jarak 3,5 Km dari garis pantai. } \\
\text { Pada tanggal } 4 \text { September } 2016 \text { terjadi } \\
\text { banjir di Jalan Soeprapto dan Jalan } \\
\text { Branjangan hal ini disebabkan oleh } \\
\text { saluran air tidak mampu menampung } \\
\text { debit air hujan, selain itu juga } \\
\text { dikarenakan meluapnya Kali Banger } \\
\text { (Kelurahan Purwodinatan). } \\
\text { Selain itu juga disebabkan drainase } \\
\text { yang sudah ada tida terawat penuh } \\
\text { dengan sampah daun dan sampah } \\
\text { plastik }\end{array}$ & $\begin{array}{l}\text { Saat ini (tahun 2018) sedang dilakukan penataan saluran } \\
\text { drainase di Jl. R. Suprapto, dengan harapan permasalahan } \\
\text { genangan di jalan utama ini dapat teratasi. }\end{array}$ \\
\hline $\begin{array}{l}\text { Terjadi amblesan tanah di Kawasan } \\
\text { Kota Lama Semarang, terjadi } \\
\text { penuruna tanah 2-4 cm/th di } \\
\text { Kelurahan Purwodinatan dengan luas } \\
24,415 \text { ha serta kelurahan } \\
\text { Tanjungmas dengan luas area } 5,129 \\
\text { Ha. }\end{array}$ & \\
\hline $\begin{array}{l}\text { Aktivitas lalu lintas yang tidak sesuai } \\
\text { dengan daya tampung lingkungan } \\
\text { mengakibatkan getaran pada jalan dan } \\
\text { nantinya akan membahayakan } \\
\text { keberlangsungan bangunan-bangunan } \\
\text { konserfasi yang ada di sekitarnya, hal } \\
\text { ini terjadi sepertii di Jalan Mpu } \\
\text { Tantular, Jalan Cenderawasih dan } \\
\text { Jalan Soeprapto, }\end{array}$ & $\gamma^{y}$ \\
\hline
\end{tabular}

Sumber: Survey Primer dan Hasil Analisis, 2018 
Jurnal Planologi Vol. 15, No. 1, April 2018 Available : http://jurnal.unissula.ac.id/index.php/psa

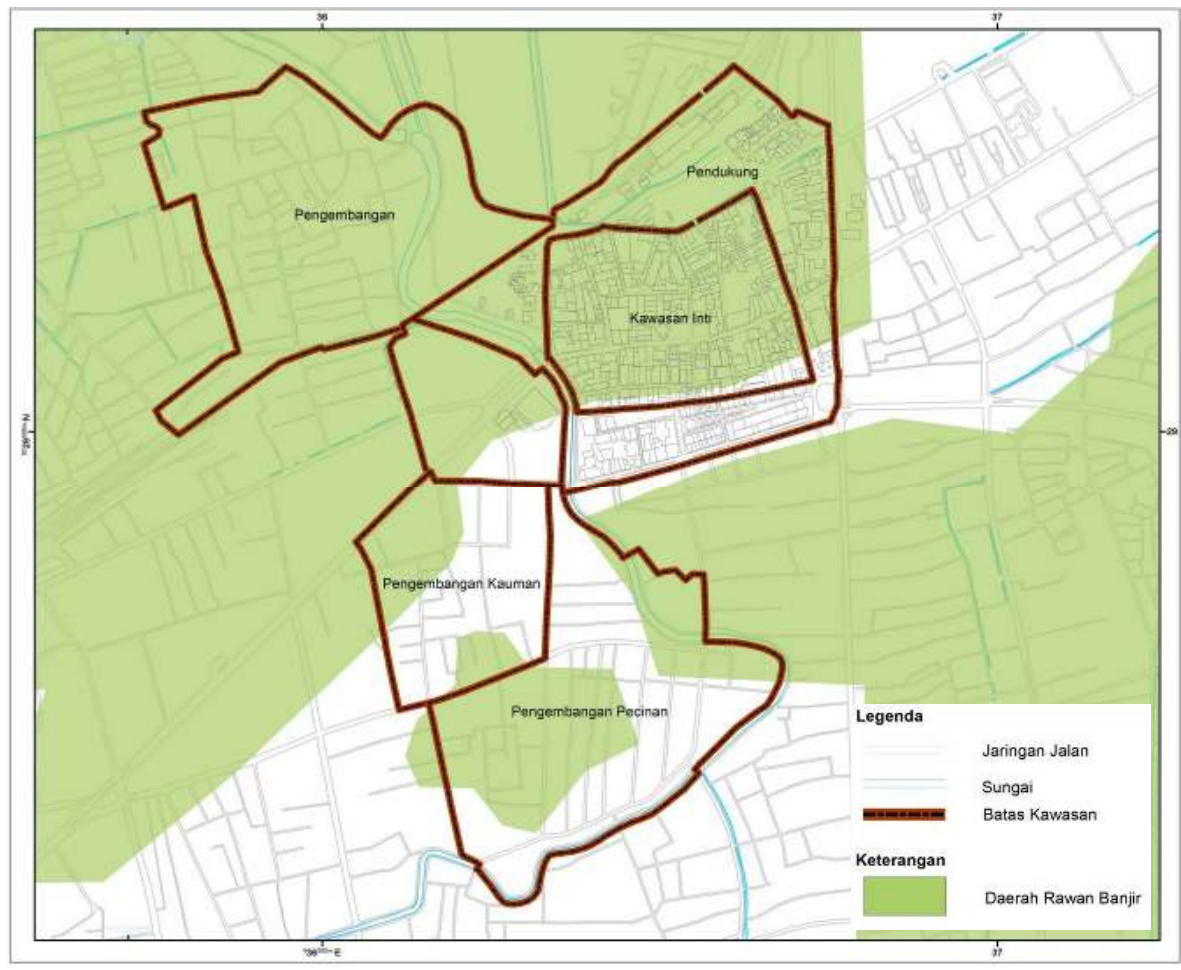

Gambar 1. Kerawanan Banjir di Kawasan Kota Lama Semarang Sumber: Management Plan Pelestarian Kota Pusaka Semarang, 2016

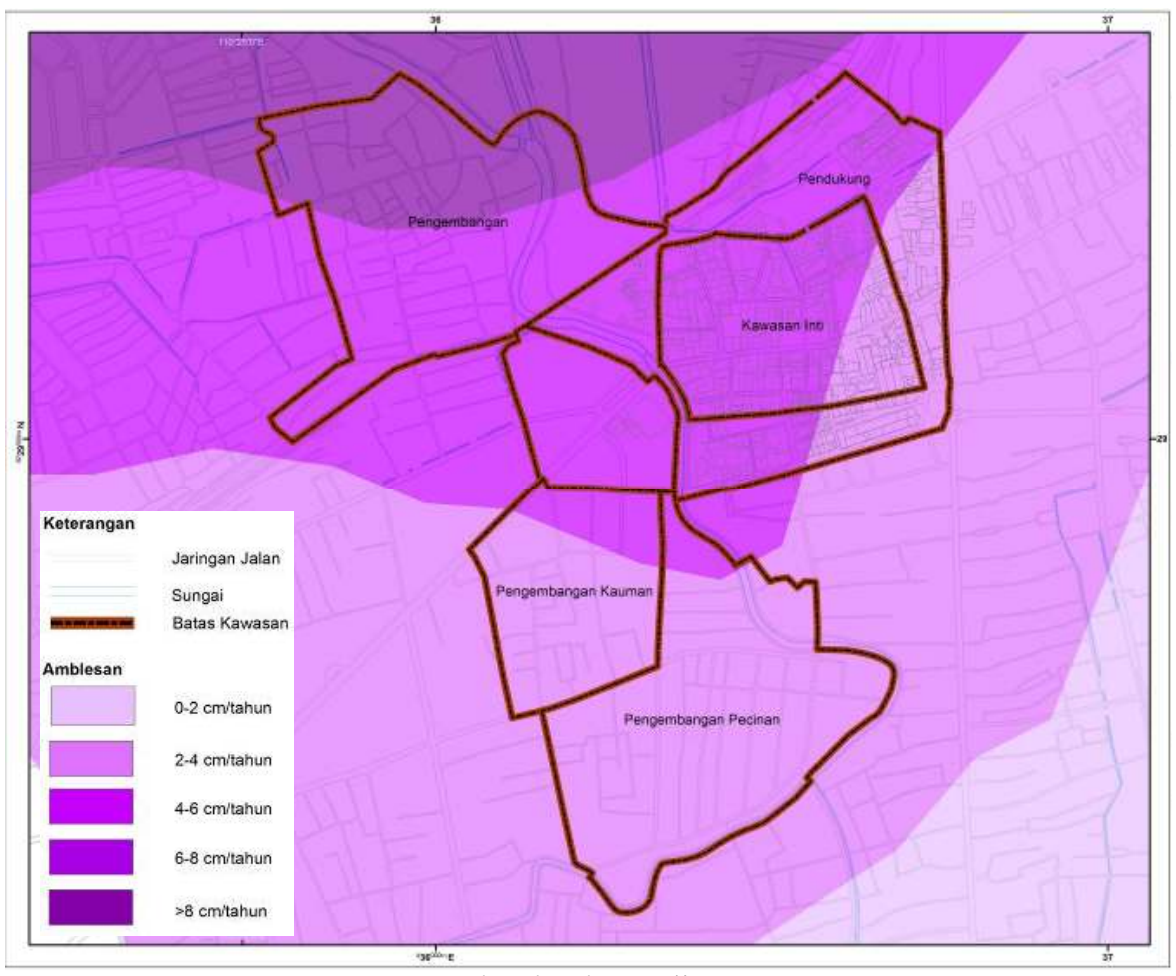

Gambar 2. Kerawanan Land Subsidence di Kawasan Kota Lama Seamarang Sumber: Management Plan Pelestarian Kota Pusaka Semarang, 2016 
Jurnal Planologi Vol. 15, No. 1, April 2018 Available : http://jurnal.unissula.ac.id/index.php/psa

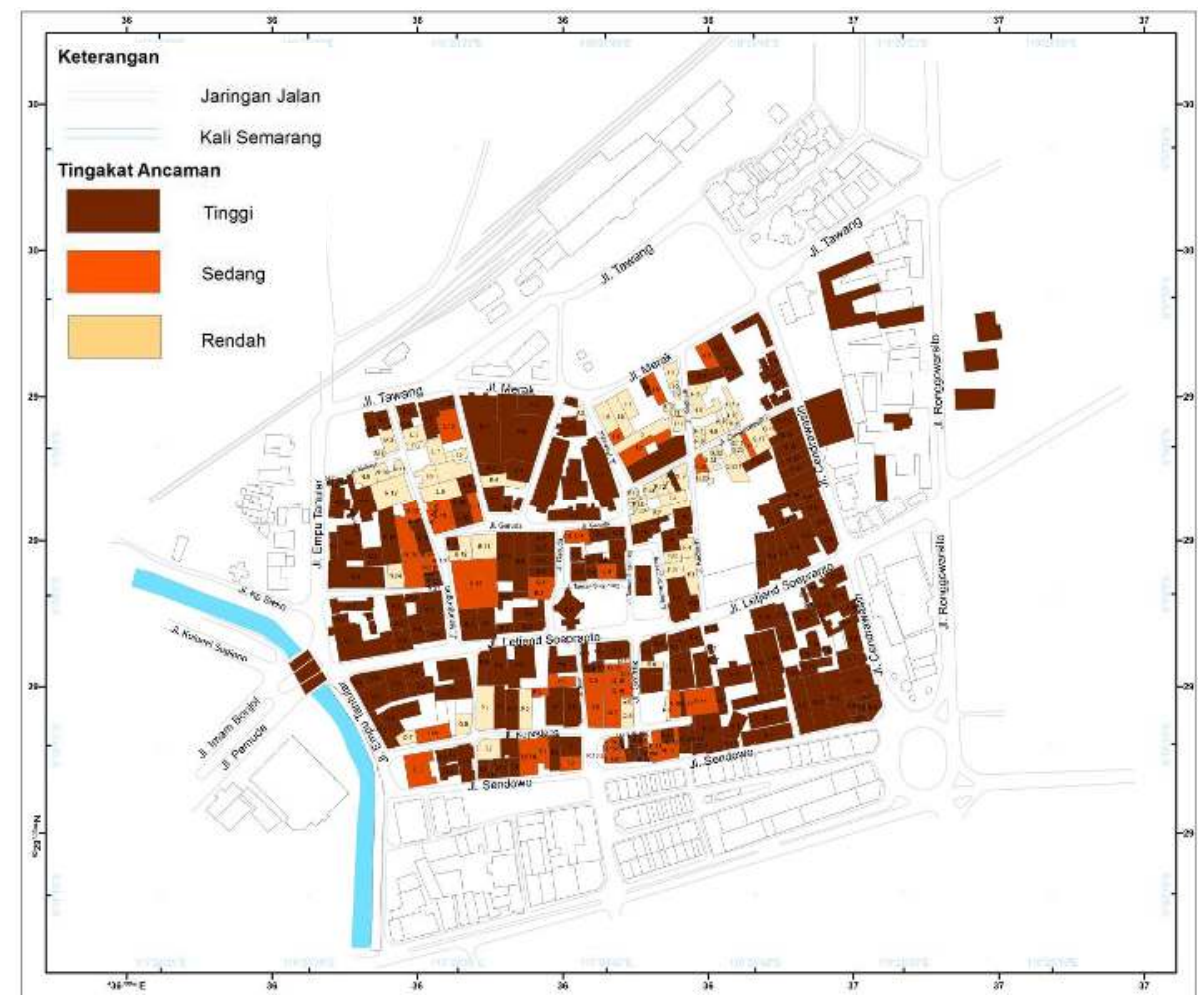

Gambar 3. Kerawanan dan Ancaman Terhadap Bangunan

Sumber: Management Plan Pelestarian Kota Pusaka Semarang, 2016

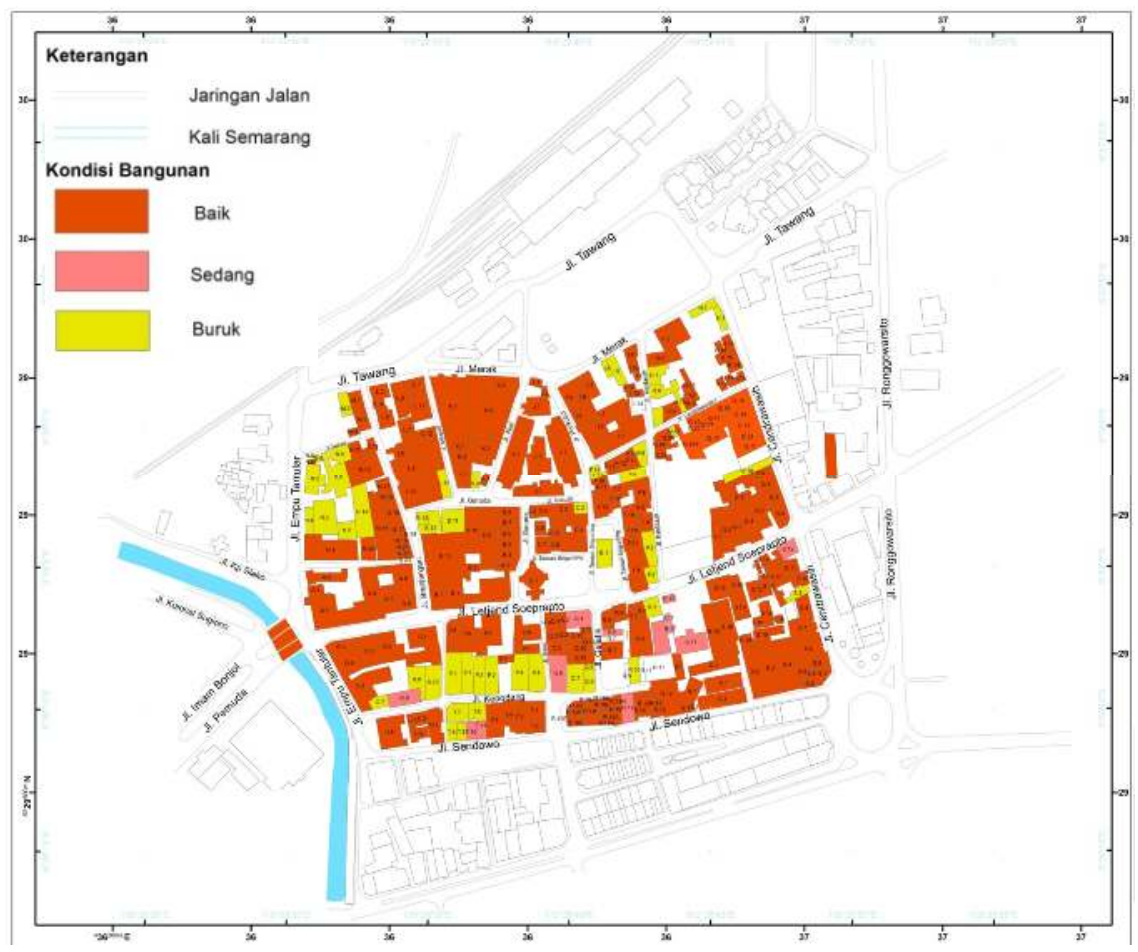

Gambar 4. Kondisi Bangunan Kawasan Kota Lama Sumber: Management Plan Pelestarian Kota Pusaka Semarang, 2016 
Jurnal Planologi Vol. 15, No. 1, April 2018 Available : http://jurnal.unissula.ac.id/index.php/psa

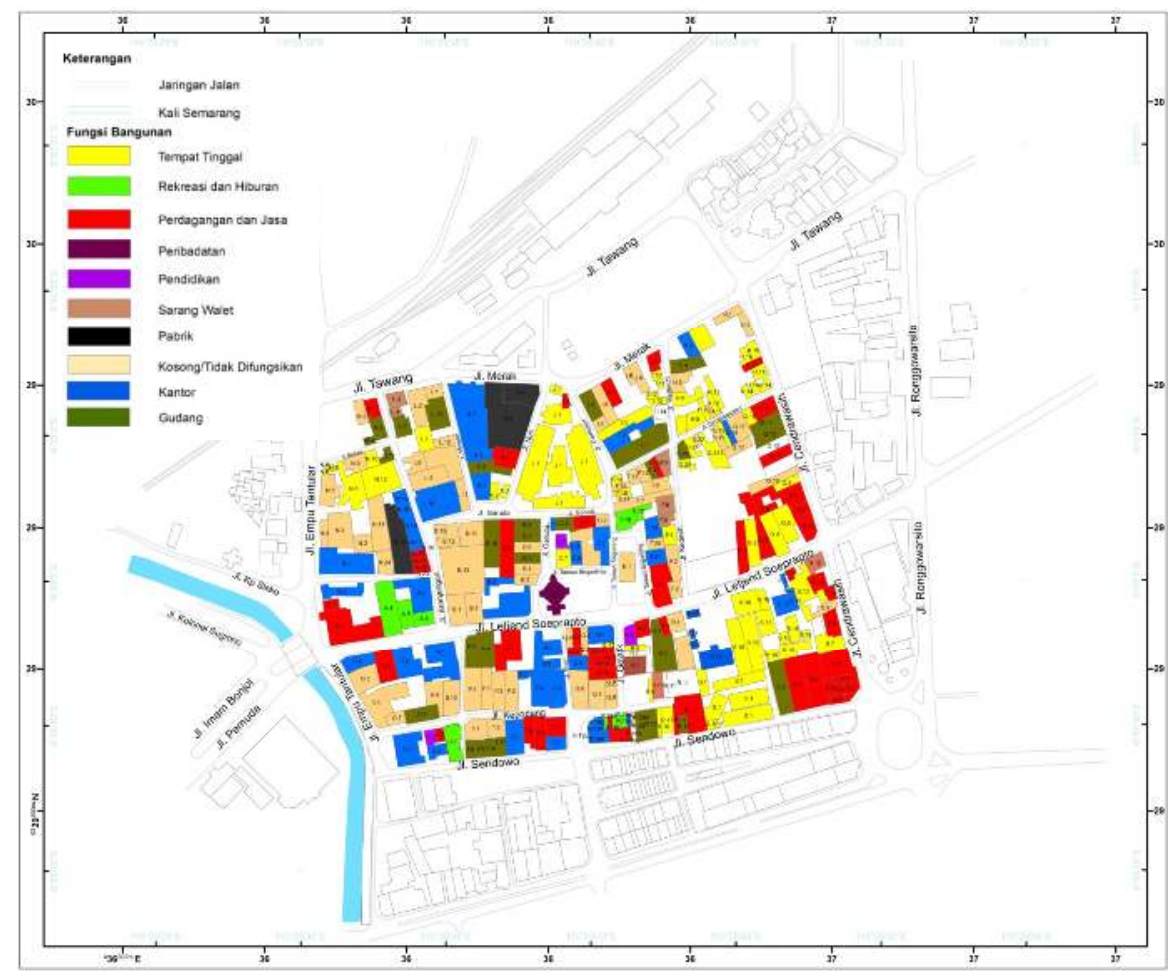

Gambar 5. Fungsi Bangunan Kawasan Kota Lama

Sumber: Management Plan Pelestarian Kota Pusaka Semarang, 2016

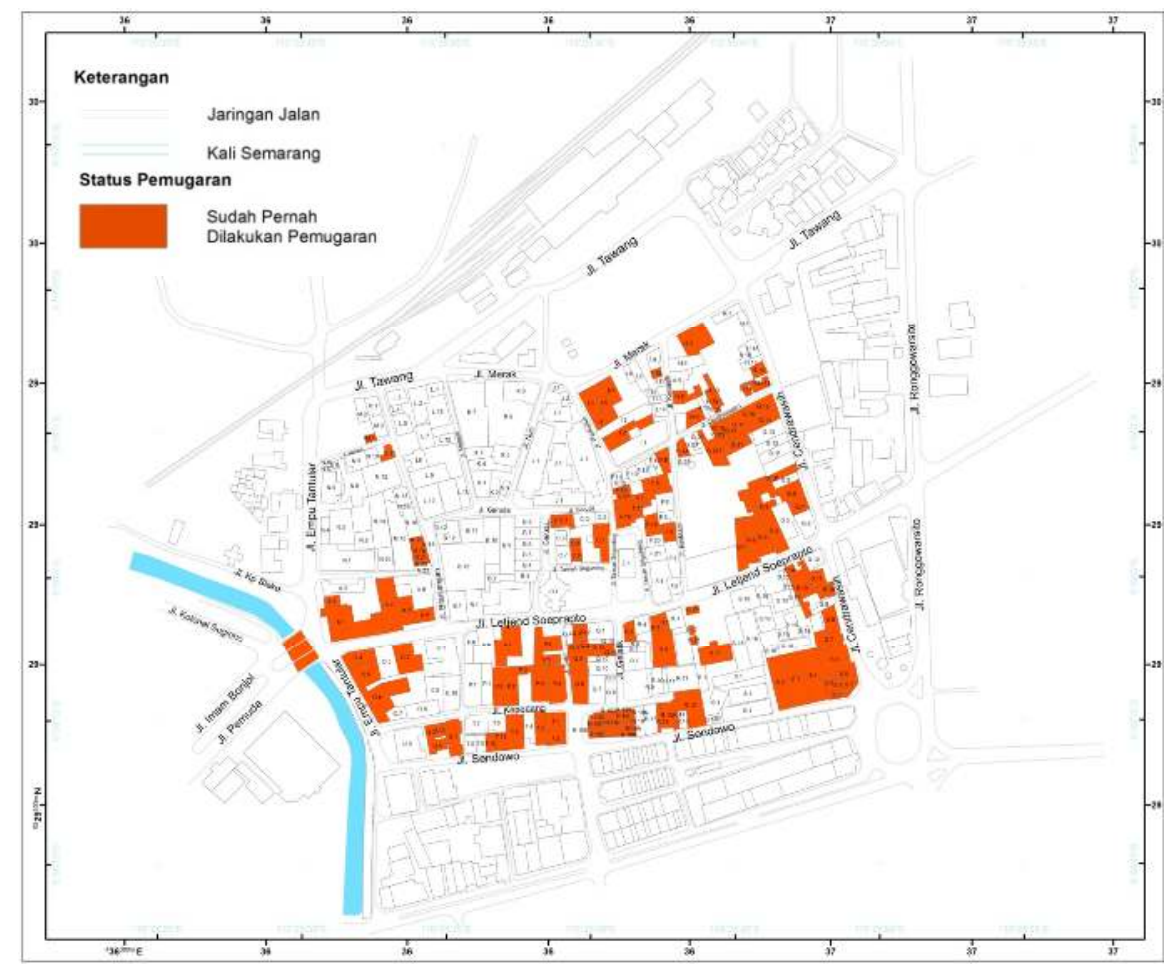

Gambar 6. Status Pemugaran Bangunan Kawasan Kota Lama

Sumber: Management Plan Pelestarian Kota Pusaka Semarang, 2016 
Jurnal Planologi Vol. 15, No. 1, April 2018

Available : http://jurnal.unissula.ac.id/index.php/psa

\section{Sosial}

Permasalahan sosial yang ada di dalam kawasan Kota Lama antara lain adalah:

- Tunawisma/gelandangan yang tinggal dengan mendirikan gubug-gubung atau memanfaatkan bangunan-bangunan kosong yang ada.

Keberadaan para tunawisma di kawasan ini sering mempengaruhi rasa aman di kawasan Kota Lama. Contohnya sebagaian ruas Jl. Merak diperuntukan sebagai kawasan city walk, namun demikian dalam perjalannya terlihat tidak berhasil karena enggannya orang untuk berjalan kaki ruas jalan tersebut.

- Aktivitas pasar unggas (burung dan ayam) dan sabung ayam di ruas Jl. Kepodang.

- Pedagang Kaki Lima (PKL) dalam kawasan, baik yang berdagang maupun yang memparkirkan gerobaknya.

Tabel 4. Permasalahan Sosial Pada Kawasan Kota Lama Semarang

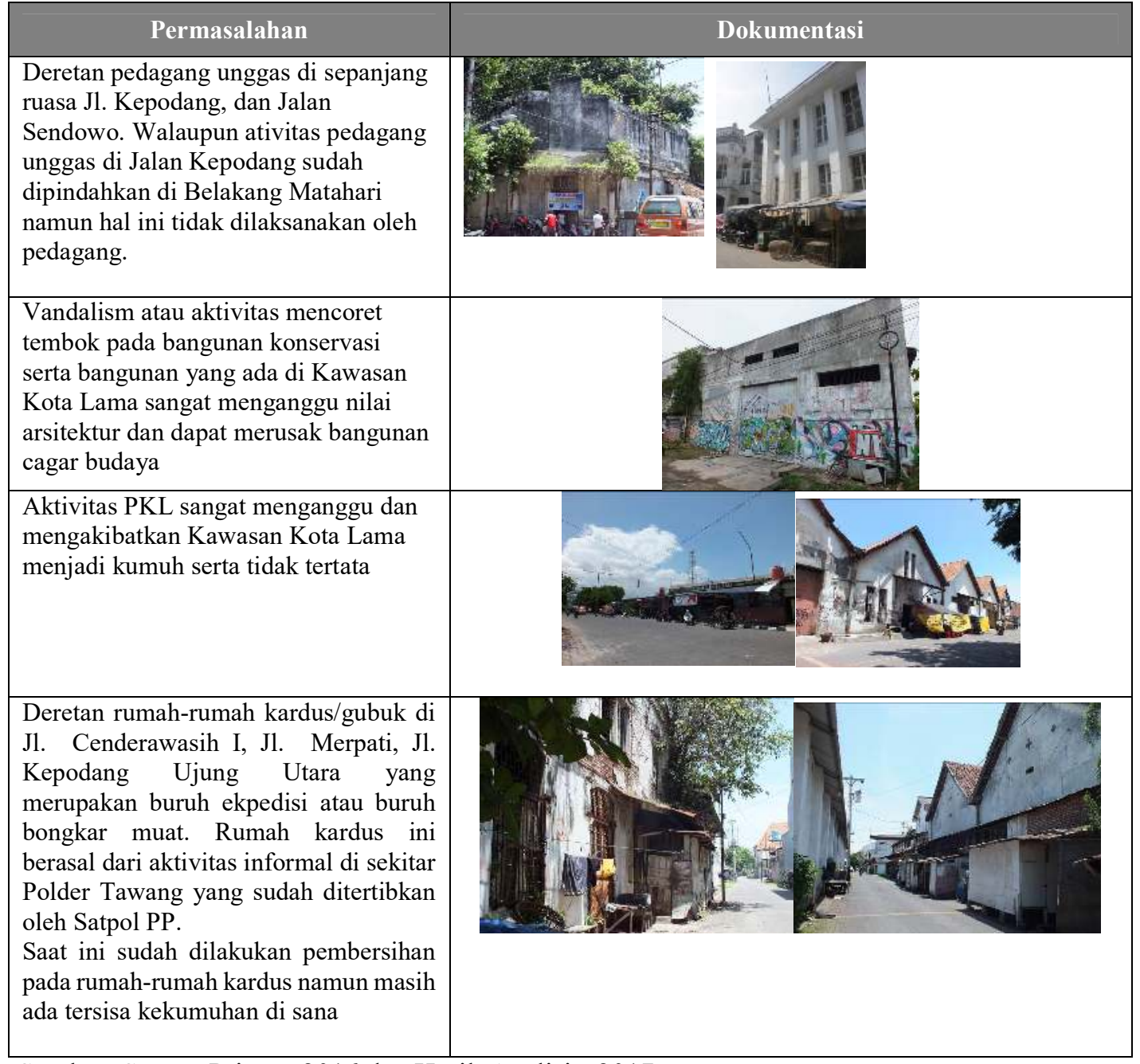

Sumber: Survey Primer, 2016 dan Hasil Analisis, 2017 
Jurnal Planologi Vol. 15, No. 1, April 2018 Available : http://jurnal.unissula.ac.id/index.php/psa

Secara keseluruhan permasalahan yang ada di Kawasan Kota Lama Semarang dapat dilihat pada pohon masalah yang kemudian dikelompokkan menjadi 4 masalah utama yang nantinya membutuhkan penanganan dalam manajemen plan pelestarian Kawasan Kota Lama Semarang. Lebih jelasnya mengenai permasalahan di Kawasan Kota Lama Semarang dapat dilihat pada gambar berikut ini: 
Jurnal Planologi Vol. 15, No. 1, April 2018

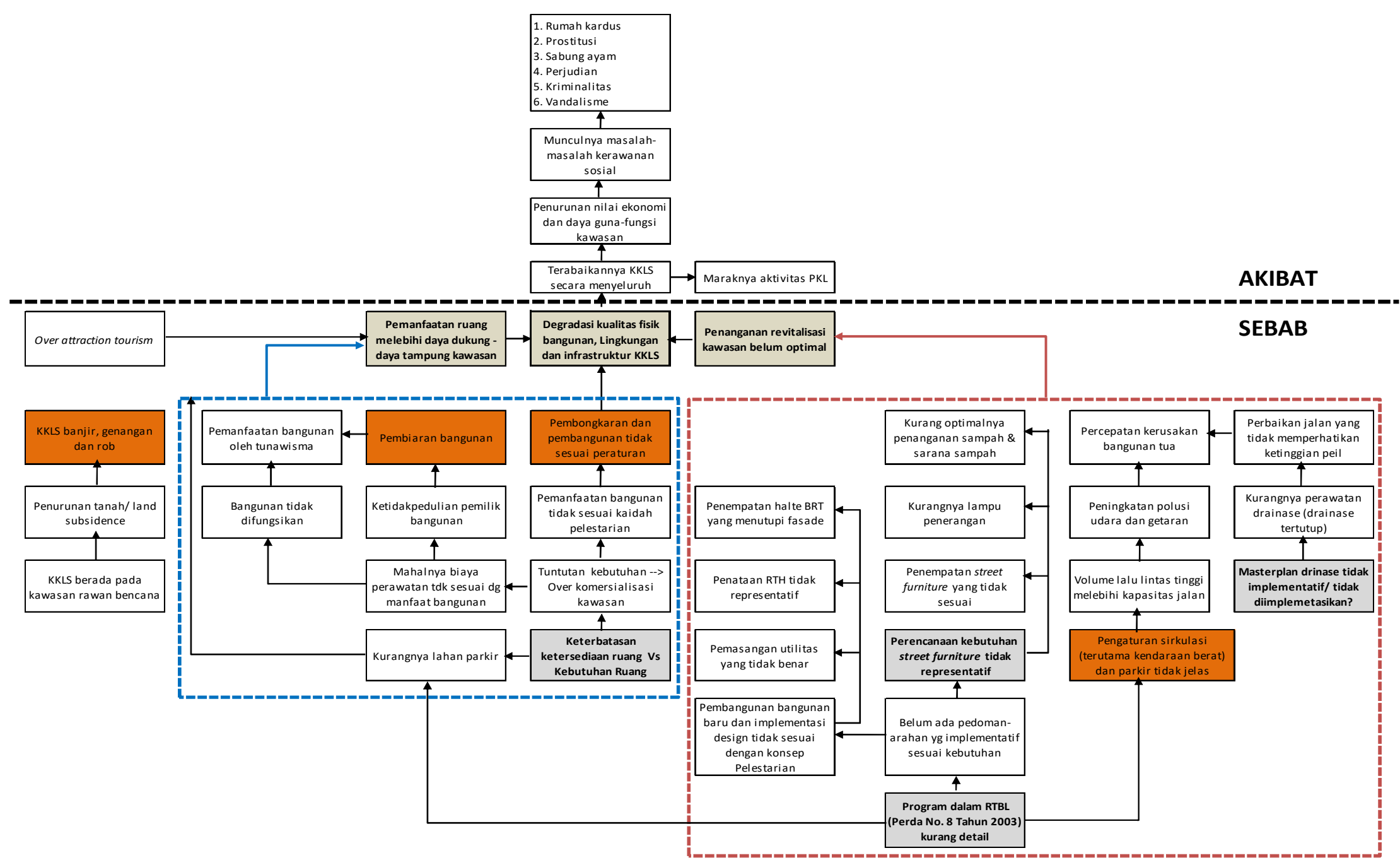

Gambar 7. Pohon Masalah Kawasan Kota Lama Semarang

Sumber: Hasil Analisis, 2017 
Kawasan Kota Lama Semarang adalah bagian kota Semarang yang dulu merupakan Kota yang dibatasai oleh benteng de Vijfhoek. Luas kawasan kota Lama ini lebih kurang 31 hektar. Di samping ada juga kawasan pengaruh yang disebut sebagai kawasan pendukung. Kawasan pendukung adalah kawasan yang berperan mendukung segenap aktivitas yang ada di Kawasan Kota Lama, dan aset-aset yang ada didalamnya masih ada hubungan/keterkaitan sejarah perkembangan dengan Kota Lama. Luas kawasan pengaruh lebih kurang 9 hektar. Sesuai dengan Peraturan Daerah No. 8 tahun 2003 tentang RTBL (Rencana Tata Bangunan dan Lingkungan) Kawasan Kota Lama jumlah bangunan yang dinyatakan sebagai bangunan konservasi adalah 105 bangunan. Penanganan pengelolaan kawasan ini menjadi tanggung jawab BPK2L (Badan Pengelola Kawasan Kota Lama).

Berdasarkan hasil identifikasi masalah yang menyertai aset diatas, kemudian dilakukan pengelompokan aset kedalam masalah-masalah yang menyertainya, dan diperoleh gambaran permasalahan yang menyertai aset sebagai berikut:

Tabel 5. Kondisi dan Distribusi Permasalahan yang Menyertai Aset/Atribut

\begin{tabular}{|l|l|c|c|c|c|c|c|c|c|c|c|}
\hline No & $\begin{array}{l}\text { Kondisi/ Masalah } \\
\text { yang Menyertai } \\
\text { Aset }\end{array}$ & $\begin{array}{c}\text { Blok } \\
\mathbf{2}\end{array}$ & $\begin{array}{c}\text { Blok } \\
\mathbf{3}\end{array}$ & $\begin{array}{c}\text { Blok } \\
\mathbf{4}\end{array}$ & $\begin{array}{c}\text { Blok } \\
\mathbf{5}\end{array}$ & $\begin{array}{c}\text { Blok } \\
\mathbf{6}\end{array}$ & $\begin{array}{c}\text { Blok } \\
\mathbf{7}\end{array}$ & $\begin{array}{c}\text { Blok } \\
\mathbf{8}\end{array}$ & $\begin{array}{c}\text { Blok } \\
\mathbf{9}\end{array}$ & Jumlah & $\mathbf{\%}$ \\
\hline 1 & $\begin{array}{l}\text { Baik/ Bisa } \\
\text { Digunakan }\end{array}$ & 15 & 33 & 14 & 18 & 12 & 22 & 46 & $\mathbf{1 7 8}$ & $\mathbf{3 3}$ \\
\hline 2 & $\begin{array}{l}\text { Buruk/Bisa } \\
\text { Digunakan }\end{array}$ & 1 & 1 & 4 & 0 & 2 & 2 & 8 & 5 & $\mathbf{2 3}$ & $\mathbf{4}$ \\
\hline 3 & $\begin{array}{l}\text { Buruk/ Tdk Bisa } \\
\text { Digunakan }\end{array}$ & 9 & 5 & 4 & 0 & 0 & 1 & 4 & 16 & $\mathbf{3 9}$ & $\mathbf{7}$ \\
\hline 4 & $\begin{array}{l}\text { Kurangnya } \\
\text { pemeliharaan }\end{array}$ & 3 & 0 & 0 & 2 & 0 & 0 & 0 & 4 & $\mathbf{9}$ & $\mathbf{2}$ \\
\hline 5 & $\begin{array}{l}\text { Fungsi tidak sesuai } \\
\text { dg lingkungan }\end{array}$ & 2 & 2 & 9 & 14 & 9 & 2 & 10 & 7 & $\mathbf{5 5}$ & $\mathbf{1 0}$ \\
\hline 6 & Pembiaran aset & 8 & 1 & 8 & 10 & 8 & 3 & 11 & 9 & $\mathbf{5 8}$ & $\mathbf{1 1}$ \\
\hline 7 & $\begin{array}{l}\text { Bangunan tidak } \\
\text { difungsikan }\end{array}$ & 4 & 0 & 2 & 9 & 5 & 2 & 11 & 7 & $\mathbf{4 0}$ & $\mathbf{7}$ \\
\hline 8 & $\begin{array}{l}\text { Pemanfaatan oleh } \\
\text { gelandangan }\end{array}$ & 6 & 3 & 5 & 6 & 8 & 0 & 0 & 2 & $\mathbf{3 0}$ & $\mathbf{6}$ \\
\hline 9 & Vandalisme & 2 & 4 & 12 & 9 & 9 & 0 & 11 & 13 & $\mathbf{6 0}$ & $\mathbf{1 1}$ \\
\hline 10 & $\begin{array}{l}\text { Lingkungan sekitar } \\
\text { kumuh }\end{array}$ & 2 & 0 & 0 & 3 & 4 & 0 & 0 & 1 & $\mathbf{1 0}$ & $\mathbf{2}$ \\
\hline 11 & PKL & 0 & 5 & 7 & 2 & 0 & 0 & 1 & 4 & $\mathbf{1 9}$ & $\mathbf{4}$ \\
\hline 12 & $\begin{array}{l}\text { Bangunan dipugar } \\
\text { diluar ketentuan } \\
\text { RTBL }\end{array}$ & 0 & 1 & 0 & 2 & 0 & 0 & 0 & 0 & $\mathbf{3}$ & $\mathbf{1}$ \\
\hline 13 & $\begin{array}{l}\text { Bangunan Baru } \\
\text { Dibangun diluar } \\
\text { ketentuan RTBL }\end{array}$ & 0 & & & & & & & & & \\
\hline
\end{tabular}

Sumber: Hasil Analisis, 2017. 


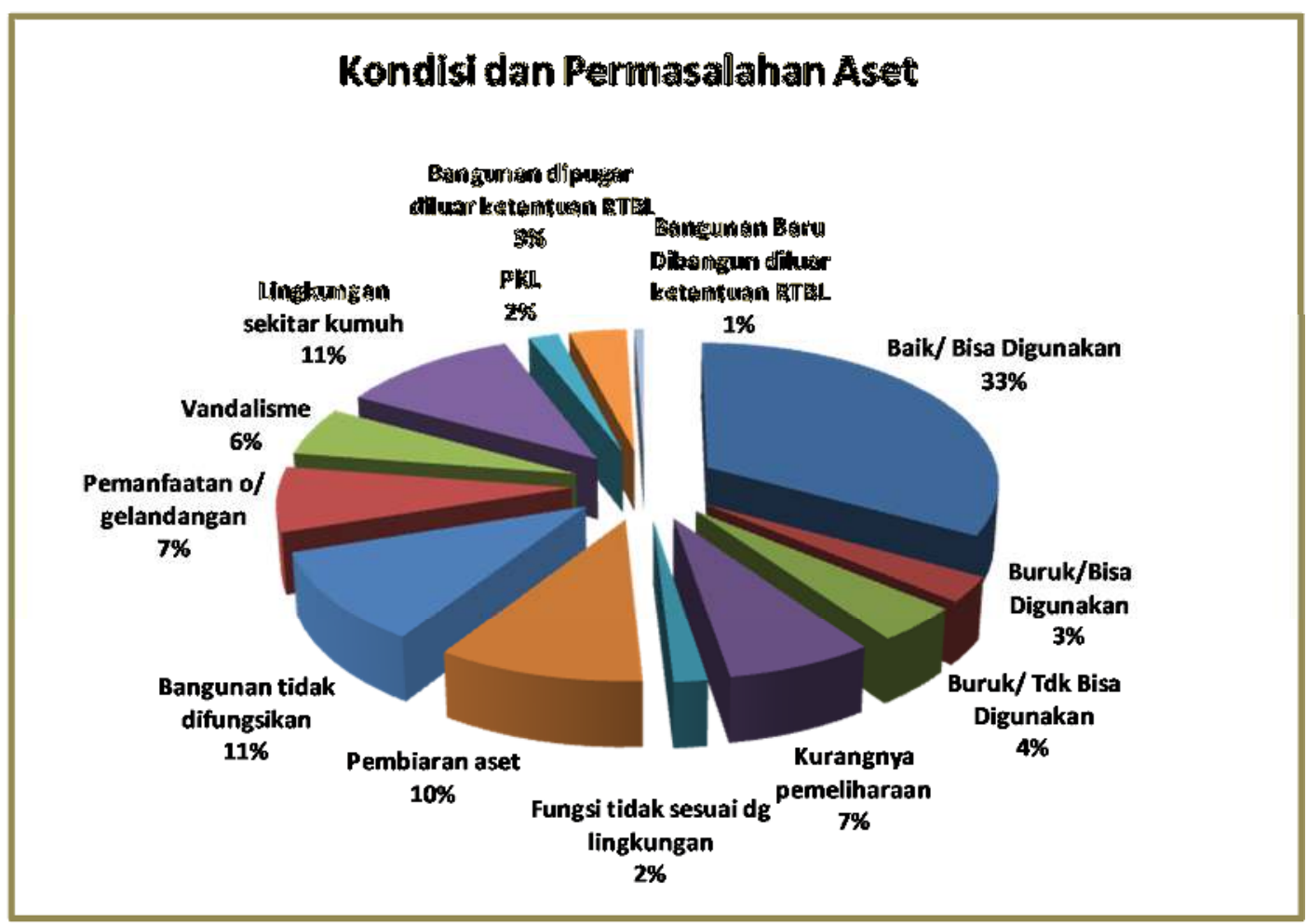

Gambar 8. Diagram Kondisi dan Permasalahan Aset/Atribut Kawasan Kota Lama Semarang Sumber : Analisis, 2017

\section{KESIMPULAN DAN SARAN}

Kesimpulan dari hasil pembahasan di atas adalah permasalahan penurunan kualitas fisik kota lama dan "mati surinya" aktivitas terutama dipicu oleh perilaku pemilik bangunan yang dengan sengaja ataupun tidak sengaja melakukan:

1. Pembiaran aset;

2. Kurangnya memelihara aset;

3. Bangunan tidak difungsikan (dibiarkan kosong); dan

4. Lingkungan yang dibiarkan kotor, tidak terpelihara (kumuh), ketidakpedulian pemilik bangunan dengan kondisi lingkungan sekitar bangunan.

Masalah pembiaran ini berujung pada semakin cepatnya kerusakan bangunan dan berkembangnya masalah-masalah sosial seperti perambahan/ penyerobotan lahan/ bangunan oleh kaum tuna wisma dan pedagang kaki lima, yang sering disebut dengan rumah kardus. Disisi lain masalah prostitusi, kriminalitas dan perjudian juga tumbuh dan berkembang di Kota Lama, akibat ketidak pedulian pemilik bangunan dan stakeholder lain yang terkait dengan kepentingan usaha di Kota Lama. 
Dari pembahasan di atas, maka permasalahan yang terjadi di Kawasan Kota Lama Semarang sangat beragam, komplek dan saling berkaitan, sehingga dapat dikelompok menjadi 4 kelompok, yaitu: masalah lingkungan, masalah bangunan, masalah sosial dan masalah tata kelola. Adapun empat kelompok tersebut jika dirincikan permasalahan seperti yang terlihat pada diagram di bawah ini.

Berdasarkan kesimpulan di atas, maka saran yang bisa disampaikan dalam penelitian ini antara lain:

a. Secara bertahap dan menerus perlu dilakukan sosialisasi mengenai proses Kota Lama Semarang sebagai nominasi World Heritage Sites, sehingga harus berbenah secara sosial, fisik, lingkungan, ekonomi dan tata kelola kelembagaan;

b. Perlu dilakukan langkah/tindakan nyata untuk menangani masalah sosial melalui penertiban rumah-rumah liar (kardus) dan pedagang kaki lima yang menempati ruang-ruang yang tidak peruntukannya (jalan, taman, saluran) menyebabkan visual Kota Lama Semarang menjadi kumuh;

c. Perlu dilakukan negosiasi dan koordinasi dengan pemilik bangunan-bangunan yang tidak terawat untuk melalukan perawatan yang perbaikan dengan cara-cara yang benar dan tepat sesuai kaidah pelestarian cagar budaya;

d. Perlu standar teknis dalam penanganan masalah fisik lingkungan di Kawasan Kota Lama Semarang, agar proses (tata cara) dan hasilnya sesuai dengan karakter lokal kawasan sebagai kawasan cagar budaya;

e. Perlu optimalisasi peran dan fungsi serta kewenangan pengelola Kawasan Kota Lama Semarang agar pengelolaan kawasan ini dapat optimal sesuai dengan harapan sebagai kawasan cagar budaya dunia nantinya.

f. Perlu dokumen kebijakan yang implementatif sesuai dengan kebutuhan pengelolaan kawasan cagar budaya dan konsisten dalam pelaksanaan programprogramnya. 
Jurnal Planologi Vol. 15, No. 1, April 2018

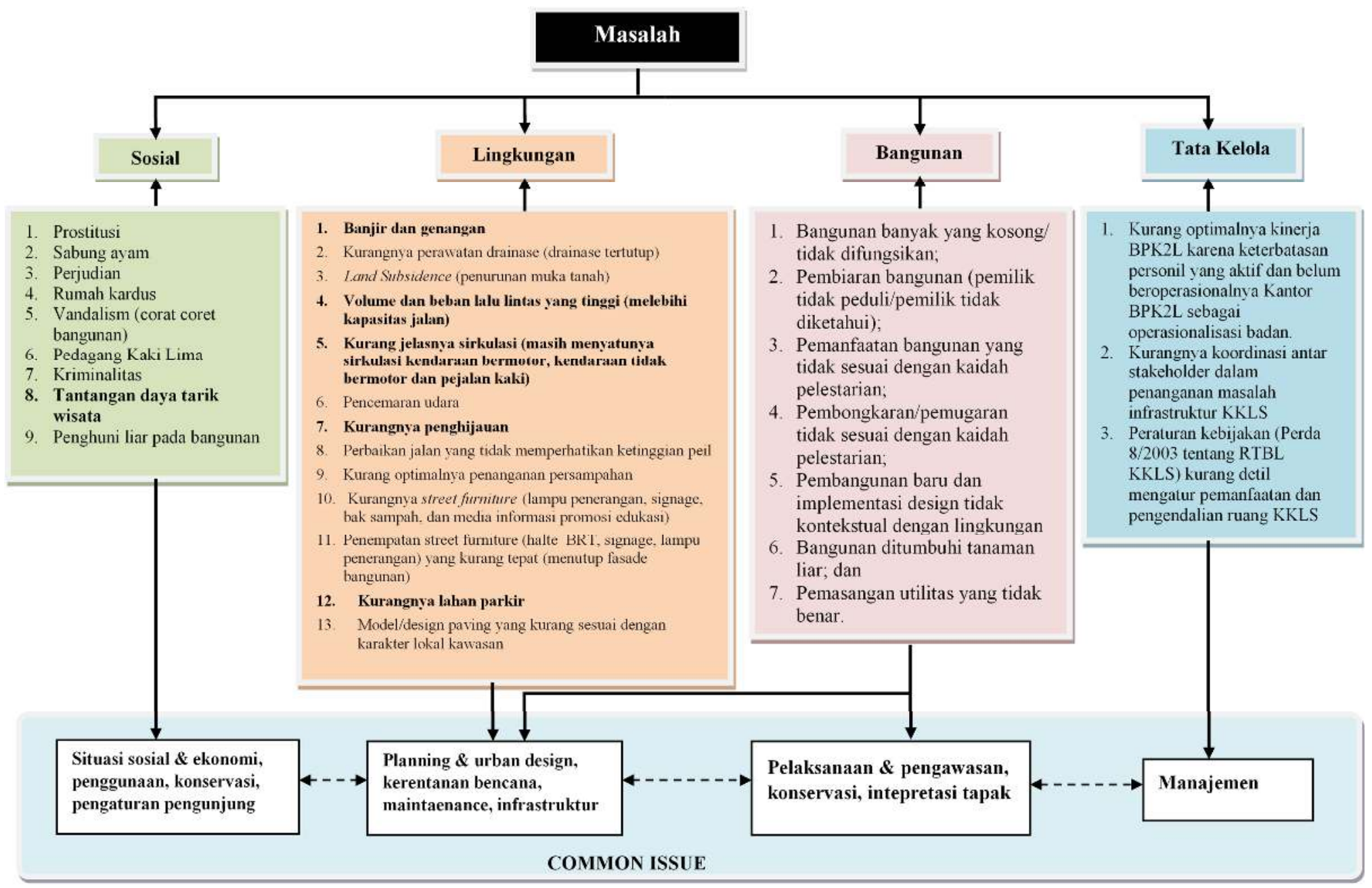

Gambar 9. Pengelompokan Masalah di Kawasan Kota Lama Semarang Sumber: Hasil Analisis, 2017

Ardiana Yuli Puspitasari, Wa Ode Sitti Khasanah Ramli I 113 Masalah Dalam Pengelolaan Kota Lama Semarang ... 
Jurnal Planologi Vol. 15, No. 1, April 2018

Available : http://jurnal.unissula.ac.id/index.php/psa

\section{DAFTAR PUSTAKA}

Adhisakti, Laretna T. (2013). Modul 2 Prinsip, Strategi dan Instrumen Penataan - Pelestarian Kota Pusaka. Balai Pelestarian Pusaka Indonesia.

Ardiana Yuli Puspitasari dan Wa Ode Sitti Khasanah Ramli, 2017, Manajemen Pelestarian Kawasan Kota Lama Sebagai Bagian Penting Kota Pusaka Semarang, di Seminar Nasional SPACE \#3, Denpasar, hlm. 328-341.

Anonim. (2003). Piagam Pelestarian Kota Pusaka.

Anonim. (2003). Peraturan Daerah Kota Semarang Nomor 8 Tahun 2003 Tentang Rencana Tata Bangunan dan Lingkungan Kawasan Kota Lama.

Anonim. (2013). Kementerian Pekerjaan Umum, Direktorat Perkotaan, Direktorat Jenderal Penataan Ruang dan P.T. Duta Citra. Program Penataan dan Pelestarian Kota Pusaka (P3KP) Kota Semarang.

Anonim. (2014). Piagam Pelestarian Kota Pusaka.

Anonim. (2010). Undang-Undang Cagar Budaya Nomor 11 Tahun 2010 Tentang Cagar Budaya, Indonesia.

Anonim. (2011). Peraturan Daerah Kota Semarang Nomor 14 Tahun 2011 Tentang Rencana Tata Ruang Wilayah dan Kota Semarang.

Anonim (2011). Bappeda Kota Semarang dan C.V. Rekayasa Jati Mandiri. Grand Design Kota Lama.

Anonim. (2016). Kementerian Pekerjaan Umum dan Perumahan Rakyat, Direktorat Jenderal Cipta Karya dan P.T. Sarana Budi Prakarsaripta. Management Plan Pelestarian Kota Pusaka.

Anonim. (2016). Balai Pelestarian Cagar Budaya Jawa Tengah. Kajian Delineasi Kota Lama Semarang.

Muhadjir, Noeng, (2000). Metode Penelitian Kualitatif. Yogyakarta: Rake Sarasin. 